\title{
ANÁLISIS DE LA PARTICIPACIÓN JURÍDICA DE LOS NIÑOS EN PROCESOS JUDICIALES VERSUS LA MANIFESTACIÓN DEL RECONOCIMIENTO DE LA PERSONALIDAD JURÍDICA E INTERÉS SUPERIOR
}

\author{
ANALYSIS OF CHILDREN'S LEGAL PARTICIPATION IN JUDICIAL PROCESSES \\ VERSUS THE RECOGNITION OF THE LEGAL PERSONALITY AND SUPERIOR \\ INTEREST MANIFISTATION'S
}

\author{
Jesús Alberto Mosqueda-Domínguez ${ }^{1} *$ iD. \\ 1. Centro de Especialización Judicial, México. chupin.culebra@gmail.com \\ *Autor de correspondencia: Jesús Alberto Mosqueda-Domínguez, email: chupin.culebra@gmail.com
}

\section{RESUMEN}

Este trabajo presenta una opinión sobre los derechos de los niños y de las niñas partiendo de postulados lógico-formal en la construcción jurídica, teniendo como eje el impacto que se genera en los proceso judiciales y como enfoque el reconocimiento de actos en un esquema de protección también de resguardo que se presentan durante y después de los procesos judiciales, optándose por un esquema dogmático de nuevos elementos que desde otras figuras que parten de la aplicación de los derechos humanos, así de los efectos jurídicos en la labor del juzgador al momento de resolver en un caso concreto.

Palabras claves: derechos de los niños; interés superior; debido proceso; enfoque; dogmático; procesos judiciales.

Cómo citar:

Mosqueda-Domínguez, Jesús Alberto. (2021). Análisis de la participación jurídica de los niños en procesos judiciales versus la manifestación del reconocimiento de la personalidad jurídica e interés superior. Revista de Investigaciones Universidad del Quindio, 33(2), 115-126. https://doi.org/10.33975/riuq.vol33n2.739

Información del artículo: Recibido: 21 julio 2021; Aceptado: 20 agosto 2021 


\begin{abstract}
This work presents an opinion on the right of children from formal logical definitions of the constitution of law, and application of the best interests of the child in processes of imparting justice, having as focus the recognition of their acts as transcendental protection and safeguard scheme, during and after legal proceedings, opting for a dogmatic scheme of new elements that from another perspective the figures of application of the law in children, as well as the legal effects that may arise in the work of the judge at the time of resolving in a specific case.
\end{abstract}

Keywords: Children's rights; best interests; due process; focus; dogmatic; judicial processes.

\section{INTRODUCCIÓN}

Desde hace una década el derecho mexicano se ha revolucionado de una manera acelerada, pues con el ingreso de nuevas figuras jurídicas en los contenidos dogmáticos de los actores jurídicos así de los elementos subjetivos que lo rodean, que nos llevan a entender de manera distinta las concepciones que comúnmente se habían conocido, estudiado y desarrollado por los distintos operadores jurídicos que nos dedicamos a la ciencia del derecho.

Por lo anterior, consideramos la presencia de nuevos modelos de los cuales el juzgador debe tener en cuenta para pronunciarse respecto del caso concreto que se le plantee y que le conduzcan a pronunciarse bajo estos nuevos parámetros que generan una nueva dinámica de cultura jurídica que es contingente, en tanto que depende de presupuestos y valores insertos en la norma aparejados a los nuevos conceptos de aplicación indispensables de tener en cuenta hoy en día

Teniendo en cuenta que los elementos antes mencionados nacen desde la aplicación de los derechos humanos como un derecho externo y novedoso, que busca encajarse no como un apartado distinto de las otras ramas de atención jurídica, sino más bien, pretenden insertarse como guía de aplicación que obliguen al juez a indicar y a generar una interpretación extensa sobre la norma jurídica planteada, buscando la eficaz aplicación deductiva del derecho coherente con los presupuestos de garantías establecidas del derecho común practicado.

Es partiendo de estas premisas queremos hacer un análisis de la figura de los niños como sujetos de derecho que llegan por su propio pie al proceso judicial visiblemente de los efectos jurídicos que le son ocasionados por las personas quienes en el derecho les representan y protegen en el campo de la vida diaria, así verbigracia sus padres que cumplen con esta obligación proporcionada por el estado regularmente dentro de los límites que establece el derecho familiar.

No así el estado y los órganos de impartición de justicia, que en este caso conciben la obligación de velar por que se protejan sus derechos dentro del proceso judicial, así de sus derechos futuros en su ámbito, pues si bien no optan por llegar de manera voluntaria a un proceso por el impedimento que se tienen en cuanto a la ley, si necesitan ser protegidos en la salvaguarda de su derecho al debido proceso como sujetos de derecho y que su participación no se encuentre reducida a simples formalidades en que la leyes debe aplicar.

Consecuencia del planteamiento descrito, redactamos este artículo con pronunciamiento dogmático del derecho de los niños, el debido proceso e interés superior del infante, 
encontrando una relación de argumentos que nos hagan denotar una nueva perspectiva para la aplicación de estos conceptos en los criterios de aplicación encontrando una nueva directriz en el aspecto de la participación de los derechos del niño y de la niña (en adelante derechos del infante) en el debido proceso, así del principio de interés superior que tiene sobre los esquemas jurídicos encontrando con ello una relevancia de asimilación sobre su entendimiento.

Así es como desde un enfoque colateral en este trabajo en primer lugar, definiremos el concepto niño partiendo de una visión que nos proporcionan otras perspectivas disciplinarias, posteriormente se reflexiona sobre los enfoques jurídicos que se plantean de manera general para conectarlo con el alcance del principio de interés superior fundado en el precepto de dignidad partiendo de un entendimiento lógico y bajo una exégesis de aplicación.

Finalmente se proporcionan conclusiones respecto del análisis elaborado en la extensión de este artículo, procurando vislumbrar elementos que busquen puntos de oportunidad para una mejor visión al momento de plasmar estos conceptos con la finalidad de fortalecer la eficacia y el entendimiento del derecho desde otras ópticas.

\section{DOGMÁTICA TRANSVERSAL}

CONTEXTUAL

El concepto de niño siempre salpica en diversos esquemas de las distintas esferas en las que se desarrolla pues va a depender de los rasgos culturales, cosmológicos y sociales, provocando que tenga un rasgo evolutivo en la historia de la humanidad, así tenemos que el concepto de derecho de los niños y de las niñas a como actualmente lo concebimos es producto de una serie de modificaciones que generan vinculación de grupos de derechos desde otras perspectivas. Pues el esquema de definiciones va mas allá de la unidimensionalidad con la que pretende concebirse ya que espera de ser relevada, para que en adhesión a leyes e instituciones lo visualicen como elemento de protección, poseyendo un apego del reconocimiento.

Aunado a mencionado esquema que nos conducen a espacios jurídicos donde se garanticé su resguardo hasta que por cronología temporal tenga que pasar a otros planos esquemáticos de derecho, así verbigracia la capacidad de ejercicio, que se adquiere una vez cumpliendo la mayoría de edad, cabe mencionar que este enfoque de miradas hacia la niñez ha sido elemento clave de lucha por parte de la sociedad que busca preservar su legado recurriendo al derecho, apuntando hacia nuevas instituciones donde la participación de los niños como sujetos de derechos tengan un grado de trascendencia individual en el campo de aplicación, de esta forma las pautas de protección no dejan atrás el enfoque pisco-afectivo en el infante que de manera ordinaria es desenvuelto en los lazos familiares a los que el derecho extiende su campo de protección para generar un margen más amplio donde en consideración también atienda grados de protección de este grupo vulnerable.

De lo anterior, notamos que el derecho del infante al ser un elemento evolutivo en diversas ramas de las ciencias, sociales y humanas tiene algunas aristas que se dirigen a la dogmática y aplicación que deben protegerse de forma conjunta para lograr una aplicación eficaz en el desarrollo jurídico que revistan de legitimidad al reconocer actos jurídicos de manera trascendental.

Tendiendo el plano referido y en busca de conocer alguna definición, decidimos apelar al derecho internacional de los derechos humanos ${ }^{1}$ en materia de protección y resguardo de los derechos del infante, plasmado en la convención 1 En este trabajo de argumentación nos apoyaremos en los que establecen los distintos tratados internacionales que obligan al estado mexicano a su aplicación, la jurisprudencia que nace de los tribunales internacionales, así como en las declaraciones que si bien no son vinculantes para nuestro país, si nos dan un punto de partida para que podamos entender mejor la aplicación de estos derechos en el contexto de la infancia y su relación con las instituciones. 
sobre los derechos del niño, en su artículo primero; "se entiende por niño todo ser humano, menos de dieciocho años de edad, salvo que, en virtud de la ley que le sea aplicable, haya alcanzado antes la mayoría de derecha."

Bajo la tesitura que nos muestra el anterior artículo, notamos que los derechos de las personas por tradición siempre tendrán un tinte cronológico en cuanto al número de años insertos en su humanidad y con base a este esquema numérico el derecho, al referirse al grado cronológico donde se reconoce en los dieciocho años a la persona, para determinar la mayoría de edad la Corte Interamericana de Derechos Humanos, ha aplicados reglas de operación y aplicación, así este tribunal establece;

La mayoría de edad conlleva al ejercicio pleno de los derechos, también conocida como capacidad de actuar. Esto significa que la persona puede ejercitar en forma personal y directa sus derechos subjetivos, así como asumir plenamente obligaciones jurídicas y realizar otros actos de naturaleza personal o patrimonial. No todos poseen capacidad: carecen de esta, en gran medida, los niños. ${ }^{2}$

A como lo ha demostrado el artículo queda fija la definición invocada por el artículo anterior, ${ }^{3}$ sin que dé cabida a otra forma de interpretación que pueda ir más allá de causar una confusión en el actuar del concepto que estamos tratando, esta situación de interpretación también la ha considerado la Ley General de Niños, Niñas y adolescentes en nuestro país, al realizar la definición que busque encontrarse fuera de confusión en la aplicación de la ley, así tenemos que mencionada ley define en su artículo quinto; 2 CoIDH, Condición jurídica y derechos humanos del niño, Opinión Consultiva OC-17/2002, solicitada por la Comisión Interamericana de Derechos Humanos, 28 de agosto de 2002, serie A, no.17, voto razonado del Juez Sergio García Ramírez, párr 41.

3 Aunado a este concepto de derecho de los niños como un concepto categórico universal, donde también incluye el concepto de niños, niñas y adolescentes, así como poner en un lado secundario el sustantivo menor con el que comúnmente se adecuo para su estudio y aplicación el derecho tradicional público y privado.
Son niñas y niños los menores de doce años, y adolescentes las personas de entre doce años cumplidos y menos de dieciocho años de edad. Para efectos de los tratados internacionales y la mayoría de edad, son niños los menores de dieciocho años de edad. Cuando exista la duda de si se trata de una persona mayor de dieciocho años de edad, se presumirá que es adolescente. Cuando exista la duda de si se trata de una persona mayor o menor de doce años, se presumirá que es niña o niño.

Estas definiciones nos pintan un panoramas de protección amplia de los derechos del infante, ${ }^{4}$ pues es un ejemplo de cómo estas prerrogativas arman una directriz que nos lleva a conjuntar otra serie de perspectivas de regulación de derechos sobre todo de manera dogmática, en primer lugar tenemos que tanto el tratado internacional, como la propia ley especifican la definición de niño con edad de dieciocho años, simultáneamente para las leyes internas el hablar de niños crea una subdivisión en cuanto a derechos de adolescentes, no así concluye con el mismo precepto de derechos dirigidos al infante para los efectos jurídicos.

De esta forma, dentro de las definiciones citadas, se prevé un plano de protección de derechos fuera de la humanidad del infante como los derechos de propiedad, que si bien es cierto, por el grado limitativo de capacidad traducida a situaciones

$4 \quad$ Ante esta restricción de capacidades en el lenguaje jurídico, es de notarse el elemento especial que caracteriza la protección del infante, más que la restricción del derecho la discriminación que se pueda observar de manera directa mediante la falta de aplicación de ley, ya que en algunos contextos se ha considerado que el termino menor puede resultar despectivo, pues hace alusión a algo pequeño, mínimo o inferior. Mas allá del empleo mismo del término "menor" (el cual se inscribe en un debate relacionado con el uso del lenguaje, y su relación con los derechos humanos); el aspecto que sería relevante analizar y poner en cuestionamiento se refiere a la concepción misma de las niñas y los niños, ya sea como simples objetos de la tutela jurídica, o bien, como auténticos sujetos del derecho. Ortega Soriano Ricardo A., Los derechos de las niñas y los niños en el derecho internacional, con especial atención al Sistema Interamericano de protección de los Derechos Humanos, CNDH, México, 2013, pag. 21. 
jurídicas no posee, se consideran protegidos por el estado, para así crear un candado donde sus derechos no caigan en la vulnerabilidad, verbigracia el caso que nos ha planteado de la definición y así pueda en este caso poseer una seguridad jurídica, traducida al lado patrimonial. Sin embargo y a interrogante del escritor. A parte del alcance cronológico ¿Aún pude existir otro elemento con el que pueda resguardarse tal persona?

Respondiendo a esta cuestión, la propia doctrina nos ha dado otro eje de parámetros que refiere a la protección tutelar, con los que podemos echar mano para la conformación del concepto de protección por consiguiente de capacidad, así tenemos que; La concepción tutela, protección se caracteriza entre otras cosas por lo siguiente:

a. Considera que las niñas y los niños son personas incapaces de ejercer por si mismas sus derechos, porque no pueden asumir la responsabilidad de sus actos.

b. Los adultos o mayores de edad se encargan de tomar las decisiones que están relacionadas o afectan la vida de la niña o niño, incluso si ello constituye una violación a sus derechos.

c. Se establecen amplias facultades para las autoridades que deben resolver asuntos relacionados con las niñas y los niños.

d. Se discrimina o se explote cualquier participación de la niña o niño en los procesos jurídicos que los involucran.

e. Las autoridades o personas que tienen bajo su cuidado a una niña o un niño, deciden en todo momento por ella o el, los sustituyen en el ejercicio de sus derechos. ${ }^{5}$

Basándonos en este parámetro de protección y recatando sobre todo la condición especial que se deduce de la ley y se transmite mediante la institucionalidad de sus actos, es que podemos

$5 \quad$ Stanley Ruth, Los niños ante la ley: juventud y justicia penal en América Latina, consultado en mayo 24 de 2021, disponible https://publications.iai.spkberlin.de/servlets/MCRFileNodeServlet/Document derivate_00001311/BIA_103_373_398.pdf, pág. 379. asumir, que el estado a pesar de tener un reconocimiento de persona al infante, continúan estableciendo ejes de protección de manera diversa, tanto en sus actos, como en sus leyes e institucionalidad, por lo que denota una presencia de sistema diferentes adscrito al orden jurídico mexicano, al tratarse de grupos inmersos en una esquema propio y especial mas allá del fundamento general de igual en la aplicación de la ley.

Este orden de aplicación de ley, trae aparejado una serie de actos entre líneas que siguen una directriz de protección y respecto, así como de promoción y garantía como obligaciones que el estado atribuye a las instituciones y las leyes, así se evita que quedan al margen de la ley como efectos pormenorizados de la manifestación de discriminación con las que puedan enfrentarse, así mandata y obliga a las autoridades bajo un fenómeno de coacción para preservar derechos, no obstante también para garantizar el pleno ejercicio de los mismos, no obviando que los incisos con los que se dirige el autor, genera un elemento de protección arropado por fundamentos legales que analizaremos a continuación.

\section{RECONOCIMIENTO DE PERSONALIDAD Y ACTOS JURÍDICOS}

Las anteriores definiciones nos han llevado a comprender que el infante posee un cúmulo de elementos que conforman su plano de aplicación y protección por el esquema completo de la legalidad que lo rodea: involucrando con ello, planos físicos, psicológicos, familiares $\mathrm{y} d \mathrm{de}$ contexto social que para el plano del derecho nos acarrea una serie de efectos legales, no visto con anterioridad, sin embargo es necesario comprenderlo desde su plano de aplicación e involucramiento al sistema de protección y el marco de interpretación.

Lo anterior debido a que en primer lugar nuestro país al ratificar una serie de tratados internacionales, obliga de facto a su 
cumplimiento de manera directa, en segundo lugar esta aplicación de tratados internacionales trae aparejado los efectos y directrices que se pueden desarrollar en el orden público y que mediante un control de convencionalidad, cuyo énfasis haremos referencia posteriormente nos lleva a un involucramiento de interpretaciones en favor del infante en los distintos rubros que involucran su desarrollo, tanto los concebidos por el estado de manera directa, como los que se dirigen a procesos subjetivos, así verbigracia los involucrados con ejes de justicia, a como es el caso. Así tenemos, que en otros instrumentos internacionales se ha hecho hincapié en elementos que dignifiquen su existencia tales como la obligación de procurarles a como lo mencionan diversos pactos de derechos humanos, así verbigracia;

El Pacto Internacional e Derechos Económicos Sociales y Culturales, en un mismo sentido, también reconoce el derecho a la familia como especio indispensable para la garantía de los derechos del niño.

Artículo 10

Los Estados Partes en el presente Pacto reconocen que:

1. Se debe conceder a la familia, que es el elemento natural y fundamental de la sociedad, la más amplia protección $\mathrm{y}$ asistencia posibles, especialmente para su constitución y mientras sea responsable del cuidado y la educación de los hijos a su cargo. El matrimonio debe contraerse con el libre consentimiento de los futuros cónyuges.

2. Se debe conceder especial protección a las madres durante un período de tiempo razonable antes y después del parto. Durante dicho período, a las madres que trabajen se les debe conceder licencia con remuneración o con prestaciones adecuadas de seguridad social.

3. Se deben adoptar medidas especiales de protección y asistencia en favor de todos los niños y adolescentes, sin discriminación alguna por razón de filiación o cualquier otra condición. Debe protegerse a los niños y adolescentes contra la explotación económica y social. Su empleo en trabajos nocivos para su moral y salud, o en los cuales peligre su vida o se corra el riesgo de perjudicar su desarrollo normal, será sancionado por la ley. Los Estados deben establecer también límites de edad por debajo de los cuales quede prohibido y sancionado por la ley el empleo a sueldo de mano de obra infantil.

El Pacto Internacional de Derechos Civiles y Políticos, establece en su artículo 24 la prohibición de discriminación y el aseguramiento del nombre y nacionalidad;

1. Todo niño tiene derecho, sin discriminación alguna por motivos de raza, color, sexo, idioma, religión, origen nacional o social, posición económica o nacimiento, a las medidas de protección que su condición de menor requiere, tanto por parte de su familia como de la sociedad y del Estado.

2. Todo niño será inscrito inmediatamente después de su nacimiento y deberá tener un nombre.

3. Todo niño tiene derecho a adquirir una nacionalidad.

La Convención Americana de los Derechos Humanos protege la esfera social y familiar en la que el niño se desenvuelve en su crecimiento y entorno;

Artículo 19. Derechos del Niño

Todo niño tiene derecho a las medidas de protección que su condición de menor requiere por parte de su familia, de la sociedad y del Estado.

Notamos como antecedente que el empuje de reconocimientos que hacen los instrumentos internacionales conlleva a que el niño posea una personalidad jurídica dentro del país donde se encuentre y por consiguiente se eleve a un rango de protección equilibrada entre otros actores que 
puedan tenerlo presente dentro de los procesos judiciales, entendiéndose la personalidad jurídica como;

El reconocimiento de que el ser humano como miembro de una comunidad políticamente organizada y jurídicamente regulada, es necesariamente titular de derechos y obligaciones; que es indispensable acoger ese estatus, con sus múltiples consecuencias, en el orden jurídico y en la aplicación de este; que no es posible restar a nadie de aquella condición primaria de "persona de derecho", dejándole al margen del orden jurídico y excluyéndole de derechos, libertades, facultades, garantías, etcétera, que son las manifestaciones, implicaciones o consecuencias del reconocimiento de la personalidad por parte del estado, sin perjuicio, por supuesto, de las restricciones o condiciones ilícitas que pudieran asignase a aquellas. Esta perspectiva ilustra sobre la personalidad jurídica en una de sus vertientes o dimensiones; la de carácter material o sustantivo. ${ }^{6}$

Esta otra expresión que nos proporciona la interpretación de la Corte Interamericana de los Derechos Humanos, el reconocimiento inalienable de la personalidad jurídica para ser titulares de derechos y obligaciones, así como para garantizar una participación en las dimensiones del derecho sustantivo y por consiguiente derechos activos en diversos entes del estado, como persona cuyos efectos jurídicos, también recaen en actos propios que requieren de condiciones propias, estos actos mencionados, se configuran cuando en la propia Convención Americana de Derechos Humanos, se establecen condiciones que respaldan derechos, cuando se menciona en los siguientes artículos;

Artículo 3. Derecho al Reconocimiento de la Personalidad Jurídica

Toda persona tiene derecho al reconocimiento de su personalidad jurídica.

$6 \quad$ CoIDH, Sentencia Comunidad Indígena Swahoyamaxa vs Paraguay, de 29 de marzo de 2006, Serie C, No. 146, voto razonado del juez Sergio García Ramírez, parr. 26.
Artículo 8. Garantías Judiciales

1. Toda persona tiene derecho a ser oída, con las debidas garantías y dentro de un plazo razonable, por un juez o tribunal competente, independiente e imparcial, establecido con anterioridad por la ley, en la sustanciación de cualquier acusación penal formulada contra ella, o para la determinación de sus derechos y obligaciones de orden civil, laboral, fiscal o de cualquier otro carácter.

Artículo 24. Igualdad ante la Ley

Todas las personas son iguales ante la ley. En consecuencia, tienen derecho, sin discriminación, a igual protección de la ley.

\section{Artículo 25. Protección Judicial}

1. Toda persona tiene derecho a un recurso sencillo y rápido o a cualquier otro recurso efectivo ante los jueces o tribunales competentes, que la ampare contra actos que violen sus derechos fundamentales reconocidos por la Constitución, la ley o la presente Convención, aun cuando tal violación sea cometida por personas que actúen en ejercicio de sus funciones oficiales.

2. Los Estados Partes se comprometen:

a. A garantizar que la autoridad competente prevista por el sistema legal del Estado decidirá sobre los derechos de toda persona que interponga tal recurso;

b. A desarrollar las posibilidades de recurso judicial, y

c. A garantizar el cumplimiento, por las autoridades competentes, de toda decisión en que se haya estimado procedente el recurso.

De este reconocimiento de personalidad también se ejercen por consiguiente actos por parte de las personas, y por qué no también de los niños, los cuales a como es conocido por todos son de trascendencia jurídica, incluso en este caso dentro del proceso, pues tanto los actores principales, también los secundarios adquieren protagonismo dentro de los procesos. Estos actos recaen dentro del esquema jurídico, pues su 
opinión y participación cabe en la trascendencia de los procesos judiciales al final que se dicta una sentencia y se reivindica el horizonte del actuar el tiempo como en el espacio, así verbigracia cuando en el infante tiene que preferirse una guarda y custodia a un solo progenitor o progenitora.

Sin embargo, seguimos notando por parte de las interpretaciones de los modelos garantistas convencionales arrojan una cierta independencia en el reconocimiento de la personalidad al momento de ejercer acción para decidir y definir derechos, o bien pronunciarse mediante el caso concreto, pues tenemos que dentro de este cúmulo de ejercicios, que hay un reconocimiento de garantías judiciales en los distintos procesos que deben ser reconocidos como derechos individuales, independientemente de la condición en la que se encuentre en un plano de igualdad para las partes intervinientes, estos procesos judiciales, se dirigen hacia un desarrollo procesal, que ante todo deben asegurar un resultado.

Así tenemos que los actos jurídicos procesales son cumplidos o ejecutados por distintos sujetos, que intervienen asumiendo diversos roles; 1) Están los que necesariamente deben intervenir y cumplir actos procesales, porque si no lo hacen no hay proceso, y 2) Están aquellos que eventualmente pueden intervenir y cumplir actos procesales. A los primeros los denominados "sujetos principales o esenciales", y a los segundos "sujetos eventuales o auxiliares".

Los principales son; a) el que tiene por misión solucionar el conflicto, y b) aquellos entre quienes se originó el conflicto; en definitiva, el juez y las partes (actor y demandado). ${ }^{7}$

Si bien es cierto, dentro del proceso judicial estos actores como los niños, carecen de un protagonismos esencial, también lo es que son

$7 \quad$ ZINNY Horacio Jorge, El concepto de debido proceso, consultado en marzo 24 de 2021, disponible en https://archivos.juridicas.unam.mx/www/bjv/ libros/9/4250/9.pdf, pp. 92-96. personas y sujetos por los qué se deciden derechos y que su participación debe ser un sinónimo de mejora en cuanto a sus derecho y su trato de protección en los procedimientos judiciales, ${ }^{8}$ es decir, la participación no debe ser secundaria, debe primarse sobre acciones de sujetos cuyo modelo engloba un lenguaje y actos distintos que hagan ejecutable una norma jurídica en cuanto a su cumplimento procurando en todo momento una participación y consenso del infante como sujeto afectado de manera directa en una esfera jurídica.

\section{DEBIDO PROCESO}

Siguiendo en el análisis de los derechos del infante ahora en el punto procesal, consideramos indispensable también entender el derecho al debido proceso donde consideramos necesario hacer un pronunciamiento, rescatando la importancia y trascendencia que este tiene sobre su esfera jurídica y ejercicio de derecho, sin embargo, lo seguiremos connotado bajo el entendimiento de elementos que continúen acordes en un lenguaje convencional de aplicación jurídica más favorecida a la dogmática y función jurisdiccional del juzgador en aplicación de tal derecho como es el debido proceso.

Por su naturaleza genuina, el debido proceso desde el derecho constitucional podemos entenderlo como un medio pacifico de solución de conflictos: como un remedio idóneo de conflictos a través de la erradicación de la fuerza ilegítima, y como un debate en el que participan dos partes con la intervención de un tercero independiente e imparcial, que interpreta y aplica la ley a cada caso concreto, regidos por una serie de principios, disposiciones y garantías básicas que aseguran la tutela judicial efectiva de los derechos fundamentales que están en juego en

8 Es la norma procesal la que establece quien, cuando, como y donde deben ser cumplidos, y cuáles son los efectos que cada uno de ellos ha de producir. Además, tiene una finalidad lícita, porque está permitida por la ley. Legamos entonces a la conclusión de que el proceso judicial, al menos objetivamente es un conjunto de actos jurídicos procesales, ídem. 
los procesos judiciales y en definitiva, garantizan un juicio justo entre las partes. ${ }^{9}$

Aquí notamos que el debido proceso por antonomasia posee una función reguladora en el carácter judicial donde los procesos insertos en la ley se dirigen a cambiar de una esfera jurídica a otra para que a la ulterioridad posea nuevos efectos jurídicos a en un contexto actualizado por parte de una norma judicial la que le proporciona el valor referido. Este valor referido, debe tener como finalidad atacar las realidades actuales que pueden presentarse hoy en día, así verbigracia, María de Jesús Conde nos expone; el desconocimiento de la psicología infantil es característico de los profesionales de la justicia, que por lo general, tratan a los niños como si fueran personas mayores, cuando se trata de la declaración de un menor de edad por lo general ni se plantea ese asesoramiento, porque considera que su conocimiento y experiencia va a ser suficiente para saber si el niño dice o no la verdad. ${ }^{10}$

Sin embargo, es tarea del juzgador como eje interpretador y ejecutor de la norma que en los procesos judiciales, considerar los planos de igualdad para la aplicación de los principios y que mediante el campo procesal de discusión de derechos, con la finalidad de que en este trance de una esfera jurídica la otra no se vean afectado derechos mas que para una mejora de quienes en

9 Entre los principios que conforman el debido proceso judicial en un Estado constitucional y democrático de derecho pueden mencionarse, entre otros, los siguientes; legalidad, bilateralidad, contradicción, impugnación, igualdad de las partes, jurisdiccionalidad, independencia judicial, moralidad del debate, humanidad, legalidad del procedimiento, inmediación inviolabilidad de la defensa, responsabilidad penal individual, irretroactividad de la ley penal, presunción de inocencia, culpabilidad, publicidad, celeridad, eficacia y economía procesal. MELENDEZ Florentin, El debido proceso en el derecho internacional de los derechos humanos, consultado en junio 16 de 2021, disponible en https://archivos.juridicas.unam.mx/www/ bjv/libros/6/2562/15pdf, pag.210.

10 Conde María de Jesús, El acceso a la justicia de niños, niñas y jóvenes, Revista Interamericana de Derechos Humanos, consultado en junio 16 de 2021, disponible en https://www.corteidh.or.cr/tablas/r25534.pdf, pág. 203. ellos en el recurso judicial ejercido es decir, que en el transcurso del proceso judicial el juzgador no solamente considere el respeto de todos los derechos, las partes y principios que enarbolan estos procesos, también se resguarde en todo este espacio principalmente los derechos en pugna.

Este esquema de protección pro personae dentro de los procesos judiciales, la aplicación de los principios y participación efectiva de las partes constantemente debe revestirse de igualdad y participación por parte del juzgador hacia la persona sin que medie un espacio de condición para acceder a la participación activa del infante cuando se note involucrado en estos procesos donde ellos como poseedores de derechos en juego son los más directamente afectados, por lo que en todo caso el juzgador debe poseer un elemento imaginaria para su integración constante, más que del aislamiento so pretexto que son niños y no adquieren un vínculo dentro de los procesos por ser limitados en su capacidad de ejercicio o bien por hacerles ver faltos de comprender las acciones en el plano procesal.

Finalmente podemos afirmar que los actos jurídicos inscritos en el debido proceso, para que sean efectivos, deben contar material y directamente con la participación de cada uno de sus actores los cuales adquieren el rango de actores masque de sujetos, cuyo significado sean limitados por la ley, para lo cual se debe tener siempre en cuenta que al referirnos a la participación activa del infante es necesario tener en cuenta lo que dice la ley en sus diversas vertientes como también el grado de contexto en el que se ve inmerso, bajo nuevas técnicas que hagan presente el entendimiento de estos elementos que rodean su participación en el proceso.

\section{INTERÉS SUPERIOR}

El interés superior del niño como un elemento dogmático inserto procesalmente, hace referencia a un cúmulo de elementos que enarbolan la protección de los derechos del infante, en cada 
una de sus fases de vida infantil, por lo que desde allí parte el presupuesto de la garantía de respeto y protección que se tiene para poder ejercer derechos y manifestar un grado de obligaciones por parte del estado que se dirija a la protección de su esfera jurídica.

Pues si bien es cierto, hablar o referirnos al concepto de interés superior, es asimilar un plano general de obligaciones que el estado nos proporciona en cada una de los distintas legislaciones permitibles a como lo hemos hecho saber en todo este trabajo de análisis, pero desde el punto de vista gramatical resulta en ocasiones vicioso por parte de los doctrinarios e impartidores de justicia, incluso hasta puede apostársele que debido a su amplitud del contenido este que puede causar un grado de confusión que haga limitar derechos más que ampliarlo como es esperado en aplicación, conduciéndonos constantemente a que se luche por permear la aplicación de su entendimiento general, pues así será más amplio un grado de protección, sin anidar una definición restrictiva que a la larga pueda parecer poco garantías para el niño en la situación de que se trate.

Lo anterior nos conduce a una afirmación aparentemente sencilla que encierra un elevado grado de complejidad por su amplio contenido, su difícil determinación y su facilidad de violentarlo. Esto es, consiste en reconocer que el menor es sujeto propietario de los derechos fundamentales reconocidos a todas las personas, los cuales están enfocados a proteger su ser o esencia de persona; en definitiva, a proteger los derechos de su propia personalidad, así como el derecho al respeto de su dignidad. ${ }^{11}$

Desde el respeto de una dignidad como concepto amplio se verá en un modelo fijo que enarbola distintos conceptos y ámbitos de desarrollo del niño, en sus distintos aspectos que al faltar o no preverles de dicho espacio o elemento lo

11 González y Rodríguez, El interés superior del menor, contexto conceptual, consultado en abril 01 de 2021, disponible en https://archivos.juridicas.unam.mx/ www/bjv/libros/6/2961/3.pdf, pág. 3. que genera directamente sería una vulneración a sus derechos, y con ello de que todas sus demás esferas se vulneren, por lo quede be actuar en un lado marco de constante de reforzamiento de los derechos del niño para así poder proveerles de dignidad. Entendiendo por dignidad en la Declaración Universal sobre Bioética y Derechos Humanos, dice que el respeto a la dignidad humana emerge del reconocimiento que todas las personas poseen un valor intrínseco, dado que todos tenemos la capacidad de determinar nuestro propio destino moral. El desprecio de la dignidad humana podrá conducir a la instrumentalización de la persona humana.

Cabe mencionar que este concepto de dignidad, también se encuentra materializado en diversos artículos que han mandatado la legislación interna y externa, de conformidad con su grado de aplicación en el derecho y el esquema de aplicabilidad de que se trate. Así tenemos que la convención americana de los derechos humanos trae a aparejadas una serie de encomiendas que nos lleva a denotar aluno de los campos de aplicación, mencionado de manera enunciativa los siguientes.

Artículo 9 1. Los Estados Partes velarán por que el niño no sea separado de sus padres contra la voluntad de éstos, excepto cuando, a reserva de revisión judicial, las autoridades competentes determinen, de conformidad con la ley y los procedimientos aplicables, que tal separación es necesaria en el interés superior del niño. Tal determinación puede ser necesaria en casos particulares, por ejemplo, en los casos en que el niño sea objeto de maltrato o descuido por parte de sus padres o cuando éstos viven separados y debe adoptarse una decisión acerca del lugar de residencia del niño.

Artículo 18 1. Los Estados Partes pondrán el máximo empeño en garantizar el reconocimiento del principio de que ambos padres tienen obligaciones comunes en lo que respecta a la crianza y el desarrollo del niño. Incumbirá a los padres o, en su caso, a los representantes 
legales la responsabilidad primordial de la crianza y el desarrollo del niño. Su preocupación fundamental será el interés superior del niño.

Artículo 21 Los Estados Partes que reconocen o permiten el sistema de adopción cuidarán de que el interés superior del niño sea la consideración primordial y:

a. Velarán por que la adopción del niño sólo sea autorizada por las autoridades competentes, las que determinarán, con arreglo a las leyes y a los procedimientos aplicables y sobre la base de toda la información pertinente y fidedigna, que la adopción es admisible en vista de la situación jurídica del niño en relación con sus padres, parientes y representantes legales y que, cuando así se requiera, las personas interesadas hayan dado con conocimiento de causa su consentimiento a la adopción sobre la base del asesoramiento que pueda ser necesario;

b. Reconocerán que la adopción en otro país puede ser considerada como otro medio de cuidar del niño, en el caso de que éste no pueda ser colocado en un hogar de guarda o entregado a una familia adoptiva o no pueda ser atendido de manera adecuada en el país de origen;

c. Velarán por que el niño que haya de ser adoptado en otro país goce de salvaguardias y normas equivalentes a las existentes respecto de la adopción en el país de origen;

Por solo mencionar un extracto de esta declaración, se deja notar primeramente que el interés superior del menor se ha referido primeramente para la preservación y como una limitante para que los derechos del infante sean transgredidos, en secuencia de una segundo término, este concepto también posee un grado de amplitud de derechos, donde en beneficio del infante los derechos deben garantizársele dentro y a largo plazo para que así como persona se permita acceder a mejores condiciones de desarrollo, ya que de lo contrario a estos estaríamos inmersos en un plano de vulnerabilidad.

Esta construcción de elemento de interés superior del menor, a como nos refiere el instrumento internacional citado, también busca que estos derechos se extiendan al disfrute del contexto en el que el infante se está desarrollando, como el contexto familiar, el contexto escolar y de esparcimiento, entre otros muchos, a lo que puede tener acceso y que son garantizables por el estado, pues de los contrario, también se vulneraria de manera colateral lo de derechos a estos elementos ya mencionados.

Ahora, apostándole al plano procesal, como atendíamos en anteriores párrafos, nos encontramos por lo regular en un espacio de tiempo donde se están disputando derechos, sin embargo, también el interés superior del infante llama a que el juzgador garantice los derechos de los contextos en el cual el infante se ve inserto para su desarrollo, es decir, el interés superior debe dar pautas para que el juzgador más que determinar lo que conviene momentáneamente, para el infante en un plano de conveniencia, prevea que estos planos estén reguardados $\mathrm{y}$ garantizados a futuro, y que el elemento de protección no solamente tenga cabida en el proceso judicial, sino que tenga contenido en los derechos que después de la resolución judicial los derechos sigan resguardados.

De esta manera el interés superior del niño se presenta ante el juzgador como una herramienta indispensable, para proteger el ejercicio de derechos del infante, así también como para limitar las actuaciones de los otros entes que puedan pesar sobre su goce y ejercicio y que el estado pueda ante todo asegurar la dignidad en el cumplimiento de deberes frente a la figura del infante, partiendo en este caso de su aplicación en los procesos judiciales.

Finalmente, tenemos que esta importancia de protección y adopción de medidas sobre el infante, se prevé por su constante situación de vulnerabilidad que se pueda generaren su esquema individual de edad y sexo, como en su esquema colectivo al referirnos a esquemas donde se desarrolla, teniendo así un cúmulo de 
normas escritas e interpretadas para alcanzar la plenitud de derechos, exigibles por sus medios de participación en los procesos judiciales.

\section{CONCLUSIONES}

El derecho de los niños debe concebirse desde distintas aristas donde se desarrolla, como el en marco biológico, familiar, socia entre otros que ayuden al derecho a aparejarse en un sistema de protección que disponga de ejercicios de derechos presenten y futuros en la esfera jurídica del infante.

Es necesaria la inserción del infante dentro de los procesos judiciales de una manera más activa dentro de los procesos judiciales, atendiendo al marco de ejercicio de los derechos, concibiéndolo como un actor más dentro de los parámetros jurisdiccionales, donde el juzgador pueda apoyarse en otras fuentes más allá de la ley para concebir, generar y respaldar los derechos de carácter individual, colectivo y procesal cuando se tiene en disputa derechos que le afecten de manera directa.
Se debe concebir el debido proceso como un derecho de protección, más que un deber procedimental, por parte del juzgador, donde bajo parámetros convencionales pueda producirse un mejor ejercicio de protección en los procesos judiciales que atienda en lado presente y futuro de los derechos en pugna del infante, atendiendo al grado de vulnerabilidad que presenta por su condición cronológica, social, familiar y de desarrollo.

El interés superior del infante se debe concebir más que como un derecho en una dogmática establecida, como una herramienta para que le juzgador disponga de todos y cada uno de los elementos necesarios que hagan valer y proteger de forma amplia los derechos del infante, así como prever el plano de efectividad de derechos en el niño, la niña, así del contexto actual y futuro en el que se desarrolla, generando un precedente de aplicación.

\section{REFERENCIAS}

1. Conde María de Jesús (2009), El acceso a la justicia de niños, niñas y jóvenes, Revista Interamericana de Derechos Humanos, consultado en junio 16 de 2021, disponible en https://www.corteidh.or.cr/ tablas/r25534.pdf

2. González y Rodríguez, El interés superior del menor, contexto conceptual, consultado en abril 01 de 2021, disponible en https://archivos.juridicas.unam.mx/www/bjv/libros/6/2961/3.pdf

3. Melendez Florentin, El debido proceso en el derecho internacional de los derechos humanos, consultado en junio 16 de 2021, disponible en https://archivos.juridicas.unam.mx/www/bjv/libros/6/2562/15.pdf

4. Ortega Soriano Ricardo A., Los derechos de las niñas y los niños en el derecho internacional, con especial atención al Sistema Interamericano de protección de los Derechos Humanos, CNDH, México, 2013.

5. Stanley Ruth (2019), Los niños ante la ley: juventud y justicia penal en América Latina, consultado en 24 de mayo de 2021, disponible https://publications.iai.spk-berlin.de/servlets/MCRFileNodeServlet/ Document_derivate_00001311/BIA_103_373_398.pdf.

6. ZINNY Horacio Jorge, El concepto de debido proceso, consultado en marzo 24 de 2021, disponible en https://archivos.juridicas.unam.mx/www/bjv/libros/9/4250/9.pdf.

7. Ley General de Niños Niñas y Adolescente

8. Convención sobre los Derechos del Niño

9. Convención Americana de los Derechos Humanos

10. Declaración Universal sobre Bioética y Derechos Humanos

11. Pacto Internacional de Derecho Civiles y políticos

12. Pacto Internacional de Derechos Económicos Sociales y Culturales

13. CoIDH, Condición jurídica y derechos humanos del niño, Opinión Consultiva OC-17/2002.

14. CoIDH, Sentencia Comunidad Indígena Swahoyamaxa vs Paraguay, de29 de marzo de 2006, Serie C, No. 146. 